\section{Experiencias de trabajo con población migrante en Montevideo. Estrategias de intervención desde la extensión universitaria}

\author{
Cecilia Garibaldi Rivoir \\ capugari@gmail.com \\ (iD) orcid.org/0000-0002-0894-1679 \\ Gonzalo Gómez Caraballo \\ ggomezcaraballo@gmail.com \\ (iD) orcid.org/0000-0002-1403-3247 \\ Facultad de Humanidades y Ciencias \\ de la Educación. Universidad de la \\ República, Uruguay.
}

RECEPCIÓN: 28/06/19

ACEPTACIÓN FINAL: 25/09/19

\section{Resumen}

En el presente artículo se abordan los desafíos específicos que asume el trabajo de extensión universitaria con población migrante en la ciudad de Montevideo. Dando continuidad a un proceso de cinco años de trabajo en la temática desde la Licenciatura en Antropología, llevamos adelante un proyecto de extensión para trabajar con migrantes de habla no hispana en el período 2016-2017, en el que nos propusimos indagar y acompañar el vínculo entre la sociedad civil y la población migrante, así como comprender $y$ fortalecer herramientas colectivas que la misma construye en la capital uruguaya como contexto de acogida. A partir de la experiencia de trabajo conjunta entre actores universitarios y la organización civil Idas y Vueltas, se generaron talleres de intercambio y diálogo sobre las demandas construidas con esta población. Tanto los resultados como las reflexiones en torno al proceso de desarrollo del proyecto son aspectos centrales a abordar en este artículo.

Palabras clave: migraciones, migrantes de habla no hispana, extensión universitaria, estrategias de intervención.
Experiences with migrant population in Montevideo. Intervention strategies from a university extension approach

\section{Abstract}

This paper addresses the specific challenges assumed in working with migrant population in Montevideo from a university extension perspective. Following a five-years work in the degree in Anthropology, we developed an extension project in which we worked with non-spanish-speakers migrants in the years 2016-2017 with the purpose of investigating and accompaning the relations between civi society and migrant population, as well as comprehending and strengthening the social networks in which this people build their integration process in Montevideo. From this joint work experience between university actors and social organization "Idas y Vueltas", we structured workshops in order to generate dialogues and participate on building demands with this population. The results of the project, as well as reflexions over its development, are key aspects of this paper.

Keywords: migrations; non-spanish speakers migrants; university extension; intervention strategies.
Cultura(s) en clave de extensión universitaria / Intervenciones 다(1)(2)(2)
Experiências de trabalho com população migrante em Montevidéu. Estratégias de intervenção desde a extensão universitária

\section{Resumo}

Este artigo tem como objetivo abordar os desafios específicos assumidos pelo trabalho em extensão universitária com a população migrante na cidade de Montevidéu, Uruguai. Continuando com um processo de cinco anos de trabalho desde o curso de antropologia, realizamos um projeto de extensão para trabalhar com migrantes cuja língua não é o espanhol. Nele, procuramos investigar e acompanhar tanto os processos de ligação entre a sociedade civil e a população migrante, quanto compreender e fortalecer ferramentas coletivas que esses migrantes constroem no seu processo de integração à capital uruguaia como lar de acolhida. Baseado na experiência de trabalho conjunto entre atores universitários e a organização civil Idas y Vueltas, criamos oficinas de troca e diálogo sobre as demandas dessa população. Tanto os resultados quanto as reflexões sobre o processo de desenvolvimento do projeto são os aspectos centrais a serem abordados neste artigo.

Palavras-chave: migrações, migrantes não falantes de espanhol; extensão universitária; estratégias de intervenção

Para citación de este artículo: Garibaldi Rivoir, C. y Gómez Carballo, G. (2019). Experiencias de trabajo con población migrante en Montevideo. Estrategias de intervención desde la extensión universitaria. +E: Revista de Extensión Universitaria, 9(11), 92-109. doi: 10.14409/extension.v9i11. Jul-Dic.8679. 


\section{Introducción}

Este artículo tiene como objetivo describir y analizar los desafíos del trabajo con la población migrante que asistió a talleres de español y alfabetización digital, coordinados por el Núcleo de Migraciones y Movimientos de Población (en adelante NEMMPO) en la Facultad de Humanidades y Ciencias de la Educación (FHCE) de la Universidad de la República (UdelaR) en el período 2016-2017. En este sentido, a partir de la realización de un proyecto de extensión universitaria, pretendemos trazar algunas líneas útiles para pensar las particularidades de la intervención universitaria con esta población. La heterogeneidad de quienes asistieron a los talleres, que en general no forman parte de las principales corrientes migratorias que ingresan al Uruguay en términos estadísticos, su relación con distintas categorías sociales, y sus efectos sobre el desarrollo de estrategias de intervención con población migrante son los principales temas sobre los que trabajaremos en este escrito.

EI NEMMPO (Departamento de Antropología Social, FHCE-UdelaR) ha desempeñado proyectos de investigación y extensión con población migrante residente en Montevideo en diálogo estrecho con la Asociación de Familiares y Amigos de Migrantes Idas y Vueltas desde el año 2014. El creciente flujo migratorio en nuestro país nos ha obligado a pensar en cómo generar herramientas teóricas y de intervención desde la academia, y desde nuestra experiencia en campo, que sean útiles para potenciar la inserción y el acceso a derechos establecido por el marco legal vigente de la población migrante en situación de vulnerabilidad en Uruguay. Los talleres semanales de español y alfabetización digital fueron parte de esas estrategias.

Llevados a cabo en una sala de informática de la FHCE, en una zona céntrica de la ciudad de Montevideo, esos talleres funcionaron como un espacio semanal regular de encuentro y de identificación de trabas y problemas comunes a la población migrante que asistía en su mayoría en las primeras semanas a partir de su llegada a Montevideo — principalmente, trámites de identificación civil, servicios del Estado y cuestiones vinculadas al mercado laboral-. La primera edición funcionó en 2015 con migrantes varones de países africanos (anglo y francoparlantes) y continuó hasta 2017 con una población más diversa. La cantidad de personas en cada instancia semanal se mantuvo entre cinco y veinte; la regularidad en su asistencia varió entre unos meses y dos años, y hubo cambios en las las características de quienes asistieron a los talleres.

Desde 2015 hasta mediados de 2016, aquellos que participaron de las clases de español fueron, principalmente, varones jóvenes llegados de países africanos, por lo general de África Occidental. Luego comenzaron a llegar mujeres; a las pocas semanas, mujeres con niños/as; personas provenientes de países latinoamericanos - Brasil y Haití- y de otros orígenes - Irán, India, países de Europa del Este, sin lograr identificar un origen nacional específico, y un caso de una mujer de origen italiano-, por lo cual la población asistente cambió en cuanto a características étnico-raciales, de género, de edad y de orígenes nacionales. En líneas generales, a lo largo de los tres años se mantuvieron las características de migrantes de habla no hispana, flujos mixtos (refugiados, solicitantes de refugio o con 
ingresos irregulares ${ }^{1}$ al país) y migrantes de orígenes nacionales con escaso flujo hacia el Uruguay (con la excepción de Brasil).

En este artículo abordamos el proceso de intervención desarrollado en el período 20162017 que acompañó esos cambios en el marco del proyecto "Buscando redes. Una aproximación etnográfica a los procesos de inserción que atraviesan los migrantes de habla no hispana y su vínculo con la sociedad civil organizada en Uruguay", ${ }^{2}$ con el objetivo de conocer las relaciones que se construyen entre los migrantes a través de la participación en organizaciones sociales y colectivos de migrantes para potenciar las estrategias de acceso al ejercicio de sus derechos. Este trabajo de producción de conocimiento desde estrategias de intervención se insertó en el Espacio de Formación Integral (EFI) "De aquí y allá" (antes llamado "Migrantes y Afrodescendientes, formas de discriminación") de la FHCE, instalado desde el año 2014 y en el cual participamos algunos de los integrantes del equipo. En el marco de este EFI se construyeron líneas comunes de trabajo con la Asociación de Familiares y Amigos de Migrantes Idas y Vueltas ${ }^{4}$, que trabaja con personas migrantes y refugiadas que llegan a nuestro país a fin de contribuir con una mejora en su acceso a oportunidades.

Las actividades estuvieron orientadas a construir espacios de intercambio y diálogo con la población migrante desde la propuesta de extensión universitaria. Hemos asumido —en la medida de nuestras posibilidades - un rol de mediadores/traductores entre la población migrante y agentes estatales, así como respecto de otros actores institucionales no estatales. La transversalidad de funciones y roles universitarios, el trabajo con organizaciones sociales y el dinamismo que presenta el trabajo con personas que llegan a nuestro país, hace necesaria la búsqueda de herramientas y estrategias que contribuyan a la permanencia de un espacio desde la universidad en conjunto con organizaciones civiles y sociales. En este marco, el acompañamiento a estas personas no puede producirse sin considerar y problematizar categorías tales como raza, género, edad, orígenes nacionales, entre otras cuestiones.

\footnotetext{
1) Frente a categorías como las de inmigrantes ilegales, irregulares, o similares, optamos por la definición de ingresos irregulares para designar aquellas situaciones en las que el ingreso al país de destino se produce por fuera de los dispositivos jurídicos previstos. Los casos a los que nos vimos enfrentados en nuestro trabajo referían generalmente a problemas asociados a visados, ingreso por puerto de polizones y/o procesos de solicitudes de refugio que no derivaron en el estatus de refugiado.

2) Proyecto financiado en el programa "Proyectos estudiantiles de extensión universitaria" de la Comisión Sectorial de Extensión y Actividades en el Medio, UdelaR.

3) "Los EFI conjugan en prácticas concretas los contenidos de las diversas disciplinas, saberes y funciones universitarias. En ellos se articula e integra la enseñanza, la investigación y la extensión. Asimismo, son prácticas que articulan distintas disciplinas y el saber académico universitario con el saber popular o no universitario" (http://www. fhuce.edu.uy/index.php/extension/efis).

4) Idas y Vueltas comenzó a funcionar con familiares y amigos de uruguayos que emigraron en el contexto de la crisis de 2001-2002. En los últimos años, la mayor parte de sus esfuerzos se destina al trabajo directo con población que llega a Montevideo y sufre distintas vulneraciones de derechos y al trabajo de construcción de una agenda en el marco de la migración como derecho humano. Luego de varias mudanzas por organizaciones sociales y religiosas que prestaban sus espacios físicos, en el año 2018 se consiguió una sede propia por un tiempo más prolongado y para su uso exclusivo (una casa que fue acondicionada gracias a donaciones y trabajo voluntario) en la que funcionan instancias semanales de encuentro, asistencia y proyectos de trabajo. Salvo situaciones excepcionales (y muy recientes), no recibe fondos fijos más que por las colaboraciones de sus asociados. Tras situaciones que generaron enormes dificultades con instituciones del Estado en la frontera sur con Brasil en Chuy-Chui, Idas y Vueltas tiene una presencia estable y de trabajo permanente en ese lugar.
} 
A partir de nuestra experiencia, tomaremos algunas preguntas que guiaron nuestra estrategia de intervención: ¿cuáles son las estrategias de intervención que desarrollamos? ¿Para qué población? ¿Cómo fue el proceso de construcción de la demanda y el problema de intervención? ¿Cómo operan las categorías de raza, género, origen nacional, lengua, clase y edad en esa construcción? ¿Cómo dialoga esta delimitación con la construcción de identidades de los sujetos en cuestión? En este sentido, y pensando en el diálogo de la extensión universitaria con las organizaciones de la sociedad civil, nos proponemos reflexionar sobre las relaciones que se establecen entre los movimientos sociales y la construcción de demanda por medio de las prácticas de extensión.

\section{El trabajo de extensión universitaria con población migrante}

Lejos de la linealidad del determinismo económico, sostenemos, con Sassen (2006), que es necesario comprender la migración como el producto social de un conjunto de interacciones que operan en la vida de las personas en contextos específicos. Al mismo tiempo, es importante problematizar las nociones que se proyectan y las representaciones que se ponen en juego sobre la figura del "migrante" en la sociedad receptora (Sayad, 2010). Una perspectiva que padece de una "miopía estadocéntrica" (Llopis, 2008:108) entiende a los sujetos migrantes bajo las categorías dicotómicas de emigrantes/inmigrantes, dualismo que emana de un nacionalismo metodológico, un esquema de interpretación que no consigue desviar el foco del estudio de lo migratorio del territorio del Estado-nación y obtura la posibilidad de construir interpretaciones, conceptos y categorías más complejas del fenómeno que excedan estas fronteras. Esta perspectiva de análisis y de producción de conocimientos simplifica el fenómeno que constituye la movilidad humana como legado de enfoques etnocentristas-coloniales que se han centrado en la inmigración y en sus efectos y no en la emigración, sus causas y consecuencias (Sayad, 2010). Es por ello que hablamos de "movilidad humana" -que abarca extranjeros, migrantes y refugiados - o de "migrantes".

Como bien señala Tilly (2000), las posiciones en las que se encuentran los individuos en la estructura están construidas sobre diferencias jerarquizadas; las desigualdades sociales responden a una estructura racista, heteropatriarcal y capitalista, agregaremos. Es por ello que tanto la categoría racial como la de origen nacional ordenan a la población migrante colocándola en lugares de la estructura social que determinarán sus posibilidades de acceso a bienes y servicios en Montevideo. A este respecto, siguiendo a Grimson (2011), existe una asociación entre la noción de "nacionalidad" y la de "cultura". La nacionalidad aparece como un atributo imprescindible para formar parte de una nación y adquirir derecho a la ciudadanía. El binomio nacionalidad/ciudadanía excluye a la población migrante en tanto no haya obtenido su residencia legal en el país donde se radicará, al tiempo que identifica cualidades para colocarla en lugares reconocibles. La homologación a población nacional en situación de calle por parte de funcionarios públicos, la sorpresa en la población local al conocer los capitales lingüísticos o las trayectorias educativas (en algunos casos, de nivel terciario), o la apropiación de categorías como "africano" (categoría que se proyectaba sobre algunas personas de Haiti) y la disolución de categorías como las de origen nacional observadas en instancias específicas de los talleres (en el armado de fichas con datos personales para entrevistas de trabajo, por ejemplo) por parte de los mismos migrantes son algunas de 
las instancias en las que detectamos las operaciones conceptuales mencionadas. La raza fue un elemento especialmente significativo para establecer continuidades entre situaciones comunes - fácilmente transformadas en dificultades - que presenciamos desde el equipo de trabajo o a las que accedimos por el relato directo en las instancias propuestas en nuestra intervención. A medida que el grupo con el que trabajamos se volvía más heterogéneo, observamos que la lengua era también un denominador común en muchas situaciones que generaba dificultades en el contexto de llegada (incluso sobre aquellos/as migrantes sobre quienes no se identificaban marcadores raciales claros y no era incluidos en la categoría de "africanos").

En 2009, la balanza migratoria en Uruguay comenzó a inclinarse y eran más las personas que ingresaban que las que salían del territorio desde mitad del siglo XX. Aunque se han elaborado algunos datos estadísticos sobre poblaciones que ingresaron al país en los últimos años (MIDES, 2017), existen problemas en términos cuantitativos y estadísticos para caracterizar a las personas con las que trabajamos, provenientes de Nigeria, Camerún y Sierra Leona en un inicio; más adelante, de Tanzania, Angola, India, Irán, Turquía, Haití, entre otros. A partir de investigaciones con migrantes y refugiados recientes (Uriarte, 2007; Uriarte y Ramil, 2016; Uriarte y Montealegre, 2018) se pueden trazar jerarquizaciones, construcciones estigmatizantes y formas de asimilar —o su imposibilidad — que responden a claras continuidades históricas en el trato de la diferencia en el marco del Uruguay como Estado-nación: la sobredimensión de la inmigración (en especial cuando refiere a contingentes poblacionales altamente racializados, familias musulmanas o provenientes de regiones con conflictos armados) y las políticas de visados — que siguen siendo exigidas para gran parte de los países africanos, del sur asiático, de Medio Oriente, Cuba, Dominicana y Haití- son algunos de los fenómenos que encuentran correlato en las condiciones de vida y dificultades para tramitar residencias de esas poblaciones una vez en Uruguay.

La promulgación de las Leyes 18.0765 y 18.2506 sobre Refugio y Migración, respectivamente, refleja una visión de la migración y el refugio como derechos humanos, garantizando los derechos de la población migrante en igualdad de condiciones con la población nacional. Pero, a pesar de lo consignado en estas leyes, en nuestro país, en la actualidad, un importante número de migrantes encuentra su ejercicio de derechos limitados por disposiciones administrativas específicas, por mecanismos y acciones institucionales o por la ausencia de políticas específicas (Uriarte y Ramil, 2016; Fossati y Uriarte, 2017; Uriarte y Urruzola, 2018). A las vulnerabilidades que presentan diferentes sectores de la población migrante o nacional se suman especificidades y situaciones de vulnerabilidad generadas por el contexto de desplazamiento propio de la movilidad. Mediante nuestro trabajo, observamos cuán necesaria era la presencia de un acompañante uruguayo/a en distintos mostradores del Estado para

5) Promulgada en el año 2006, la Ley 18.076 "Derecho al refugio y a los refugiados" es la primera sobre refugio en Uruguay. Ampara el derecho de las personas a solicitar refugio independiente de su condición de género, raza, origen nacional, clase, edad, religión, así como señala los criterios de reconocimiento de la persona refugiada. Disponible en: https://legislativo.parlamento.gub.uy/temporales/leytemp7548768.htm

6) Promulgada en el año 2007, la Ley 18.250 sustituye a la ley vigente hasta ese momento, cuyas últimas modificaciones se remontaban al año 1936. Esta ley reconoce los derechos de la población migrante en pie de igualdad con la población nacional y se sostiene sobre una perspectiva clara de la migración como un derecho. Disponible en: https:// legislativo.parlamento.gub.uy/temporales/leytemp4654312.htm 
que fueran ejecutadas acciones previstas en el marco de la ley, incluso en acciones básicas, como la afiliación al sistema de salud pública con todos los requisitos cumplidos y los formularios escritos y firmados. Asimismo, escuchamos diversos relatos sobre las dificultades generadas por no poseer un domicilio estable (considerando que en gran número viven en pensiones, hay personas que pasan la noche en refugios, e incluso en algunos casos han pasado noches en la calle). Diferencias lingüísticas, marcadores raciales, distancias culturales e incluso religiosas, fragilidad en las redes sociales y la no pertenencia al colectivo nacional constituyen algunas de esas especificidades que visualizamos en distintas instancias y a las que en cierta medida también respondió la generación de un espacio en la FHCE con personas conocidas y conexión a Internet.

Emprendimos nuestro trabajo con la población migrante considerando los fenómenos de discriminación xenófoba y racial, así como las demandas en torno a las dificultades que iba identificando en sus procesos de integración a la sociedad uruguaya. Cuando hablamos de "trabajo" nos referimos a procesos de intervención y de trabajo conjunto de actores universitarios con organizaciones de la sociedad civil, desde una perspectiva de la integralidad de funciones de enseñanza, extensión e investigación. Este abordaje teórico-metodológico asume el especial desafío de repensar el vínculo sociedad-universidad, en donde reconocemos al saber cómo construcción colectiva en un giro epistemológico que nos permita considerar que la producción de conocimiento científico lejos de ser neutra, requiere de compromisos que apunten a procesos de transformación social (Sarachu, 2004). Además, esta perspectiva implica un encuadre metodológico dialéctico que pondera justamente las formas de construcción de conocimiento conjuntas, con metodologías que habiliten un diálogo entre los saberes que poseen los diferentes actores (Jara Holliday, s/f). En este sentido estuvo orientado nuestro trabajo, de modo de generar conocimiento sobre las estrategias que desarrollan las personas migrantes en Montevideo para entablar sus redes y de crear espacios de intercambio entre población no uruguaya en Montevideo donde puedan pensar formas de atender sus demandas.

El contacto y la centralidad otorgados a la organización Idas y Vueltas se refugia, en gran medida, en el entendimiento del rol protagónico que tienen las organizaciones de la sociedad civil en el proceso de construcción de las redes de migraciones como actores fundamentales en los procesos de migración una vez que ya existe una comunidad migrante en el país receptor (Sassen, 2006).

Desde el NEMMPO, el abordaje de estudio e intervención sobre el fenómeno migratorio ha estado muy marcado por aspectos teórico-metodológicos inherentes a la práctica extensionista, mayoritariamente desde una formación disciplinar en Antropología Social (Gómez, Curbelo y Uriarte, 2018). Las diversas líneas de trabajo con esta población han demostrado que la práctica de extensión ofrece un conjunto de herramientas teórico-metodológicas útiles para comprender el fenómeno migratorio y para intervenir en las problemáticas construidas social y sociológicamente a partir de él. Entre estas herramientas, destacamos la realización de talleres desde una perspectiva horizontal, orientados a construir un espacio de intercambio que responda a las demandas de las personas que concurren, con actividades participativas que fomenten el diálogo con las personas involucradas para que sean partícipes de las directrices del proyecto (Sarachu, 2004). Hubo encuentros donde desarrollamos actividades grupales (discusión de videos, de canciones, de escritura en procesador de tex- 
to, realización de curriculum, familiarización con aplicaciones de transportes de Montevideo, por mencionar algunas) y otros con actividades individuales (orientación en la realización de trámites y curriculum, envío de emails, bolsas de trabajo, entre otras).

Desde estas líneas de trabajo se entiende que la producción de conocimiento académico debe orientarse a construir conocimiento socialmente significativo mediante un diálogo necesario con las poblaciones en cuestión, sus organizaciones de la sociedad civil y sus demandas, tal y como sostienen Fossati y Uriarte (2018), pensando en la investigación e intervención sobre el acceso de la población migrante a la vivienda. De igual manera, los abordajes sobre la perspectiva de género en el fenómeno migratorio y las relaciones de cuidados transnacionales fueron construidos a partir de experiencias de extensión, como la creación de espacios específicos para mujeres migrantes, en su mayoría latinoamericanas, en la ONG Idas y Vueltas, en forma de taller de intercambio sobre esa problemática en Montevideo (Uriarte y Urruzola, 2018).

El trabajo conjunto entre Idas y Vueltas y el NEMMPO está fuertemente marcado por la construcción de líneas de trabajo conjuntas para contribuir a la identificación, comprensión e intervención de mecanismos discriminatorios que recaen sobre la población migrante en el contexto del Uruguay como país receptor (Uriarte y Ramil, 2016). Estos ejes de trabajo están directamente relacionados con antecedentes de trabajo con población afrodescendiente y migrante que visibilizan los mecanismos de discriminación racial y xenófoba hacia estas poblaciones. Destacamos el fenómeno de discriminación racial como central en el trabajo con población migrante dado que, a pesar de que los principales flujos de población que ingresan al país siguen proviniendo de los países vecinos (Argentina y Brasil), es el aumento de flujos de poblaciones de otros orígenes sudamericanos y caribeños, con altos porcentajes de poblaciones afro (MIDES, 2016), lo que se percibe como significativo en el aumento de la inmigración y el cambio de la balanza migratoria por primera vez desde mediados del siglo pasado.

Para lograr exponer algunas reflexiones en torno al proceso de trabajo, ordenamos este artículo siguiendo la cronología del mismo, de las formas de intervención, y de las problematizaciones que fuimos elaborando durante el mismo.

\section{Estrategias de intervención: definición de espacios}

Desde 2015, uno de los equipos del NEMMPO orientó su intervención hacia las áreas que Idas y Vueltas identificó como demanda para la población migrante -acompañamiento en trámites de residencia, de acceso a servicios públicos estatales, de convivencia vecinal barrial, acceso al mercado de trabajo y soluciones habitacionales-, con un segmento de la población que, en cierta medida, sobrepasaba las capacidades de la Asociación. Los talleres en la FHCE respondieron a cierta saturación de los espacios físicos ya existentes, posibilitaron el uso de computadoras con conexión a Internet y se generó una instancia en la que se pudo trabajar con barreras idiomáticas y trayectorias que presentaban problemas menos comunes para el resto de quienes llegaban a Idas y Vueltas. Casos de polizones, personas migrantes con trayectorias dispares o altamente individualizadas y solicitudes de refugio se presentaron como las situaciones más comunes, lo que se complejizó además por el hecho de no hablar español y proceder de países sin representación diplomática. 
La estrategia de intervención constó de dos acciones concretas. Por un lado, el taller de español y de informática y, por otro, el acompañamiento en la realización de trámites y pasaje por distintos entes estatales. Previmos la continuidad de un espacio inicial de español, alfabetización digital e intercambio que buscaba trabajar con aquellos/as migrantes que no hablaban español, de modo de focalizar en una característica común que presentaba continuidades en el tránsito por organismos del Estado y en la brecha entre derechos garantizados por el marco jurídico actual y su acceso real.

En este contexto, durante 2015 y 2016, por parte de estudiantes de distintas licenciaturas se fueron conformando espacios semanales abiertos de clases de español, de computación y diversos talleres en la FHCE (armado de curriculum, fotografía, entrevistas laborales, deportes), así como el apoyo a la realización de trámites (donde el no hablar español significaba un gran obstáculo). Estos encuentros, que excedieron los espacios semanales, generaron una familiarización con varias de las demandas y los desafíos que afrontaban estas personas al llegar a nuestro país. Y debido a ello se originó el proyecto sobre el cual pretendemos reflexionar.

En lo que refiere a las estrategias de intervención, empezamos por consolidar el trabajo y las experiencias previas - sistematizando y generando líneas de análisis- y apostamos a llevar adelante el taller de alfabetización digital y español — cuyo alcance no se limitó a los encuentros semanales y objetivos formales- sino que implicó un proceso de construcción de un espacio de confianza abierto a diversas actividades, diálogos y expresiones. Este fue un dispositivo particularmente fecundo para acercarnos a conocer los procesos de integración de estas personas que llegaban a nuestro país, los mecanismos de construcción de sus redes, así como las brechas entre los derechos garantizados por el marco jurídico y el real acceso a los mismos por parte de esta población.

Los talleres se constituyeron como terreno fértil para la profundización de redes y contactos entre migrantes, y allí se fueron acumulando demandas y objetivos que no necesariamente coincidían con las demandas que nosotros habíamos identificado inicialmente, aquellas que operaron como nuestro motor. Dada la apertura y el continuo diálogo entre el equipo y los actores no universitarios, las estrategias de trabajo se reorientaron; los cambios, que podrían considerarse una dificultad en la ejecución del proyecto, generaron varias aperturas. La construcción de espacios desde migrantes y de migrantes, con distintos niveles de autonomía respecto de las organizaciones existentes, en conjunto con integrantes del equipo ampliaron significativamente los alcances del proyecto.

La tarea de extensión fue a la vez una decisión y una necesidad para trabajar con un grupo de migrantes que identificaba obstáculos particulares tanto en los itinerarios burocráticos para regularizar su situación migratoria como para acceder a distintos servicios del Estado y el mercado de trabajo. Pero también presentaba dificultades específicas que, en algunos aspectos, sobrepasaba las capacidades de respuesta de parte de la sociedad civil organizada. En este sentido, este punto se volvió una demanda de Idas y Vueltas. Por un lado, a partir de la necesidad de acceder a medios informáticos, conexión a Internet y aproximación al idioma español, lo que podía canalizarse en un salón de la FHCE. Por otro lado, nos propusimos fortalecer la construcción de redes, intercambiar experiencias, información, y encontrar referentes locales para desempeñar diferentes trámites y proyectar su proceso de integración en Montevideo. 
Los ingresos recientes, los orígenes nacionales de escaso flujo hacia el país, los ingresos irregulares, entre otras cuestiones, producen situaciones no previstas de manera muy frecuente y el país receptor — tanto desde el Estado como desde la sociedad civil- se ve obligado a asumir dichos desafíos. Anulación de trámites por errores en la traducción idiomática, por el desconocimiento de lugares de origen, confusiones en la diversidad de estatus migratorio $^{7}$ y mecanismos para su regularización, son algunos de los desafíos que se traducen en la dificultad de pensar políticas públicas dislocadas del enclave nacional. Así, estas políticas no consiguen resolver los problemas que se presentan en la vida de estas personas, sino que dan continuidad a mecanismos de reproducción de discriminación como "las prácticas institucionales que llevan a la reproducción de las desventajas de la población no-blanca" ${ }^{8}$ y que identificamos como "racismo institucional" (Segato, 2006:7).

El lugar de la extensión fue clave para lograr el acompañamiento de casos específicos y el diseño de estrategias que ayudaran a identificar - a partir de cada caso y de cada ingresodificultades y potencialidades comunes, algo imprescindible para el proceso de construcción de la demanda sobre los objetivos y estrategias en este marco.

\section{Migrantes de habla no hispana: desafíos de la intervención}

En una sociedad como la uruguaya, donde la desigualdad está racialmente caracterizada y socialmente invisibilizada tras el mito igualitario (Guigou, 2000), nos enfrentamos a un desafío teórico-metodológico al momento de pensar cómo operan los mecanismos de discriminación sobre las personas con las que trabajamos. Retomamos lo planteado desde el NEMMPO por Uriarte y Ramil :

"analizar los dispositivos discriminatorios que operan combinando raza con nacionalismo no resulta una tarea fácil. Existe una dimensión de las prácticas discriminatorias que, ideológicamente informadas, toman cuerpo en la relación interpersonal y afectan de forma específica a hombres y mujeres afro, nacionales y extranjeros en función de su región de origen. Esta dimensión es fundamental para la comprensión del racismo como un fenómeno social que actualiza la desigualdad y permite su reproducción a nivel estructural”. (2016:7)

La población que en los inicios participó de los talleres estaba compuesta principalmente por varones jóvenes llegados en su mayoría de África Occidental. Aunque arribados en distintas condiciones, fue sencillo identificar, a través de sus relatos y las experiencias compartidas, diversos mecanismos de discriminación racial que operan en nuestra sociedad. Sin embargo, esta composición cambió en la medida en que quienes inicialmente participaban establecieron sus propias redes y los talleres en la FHCE se consolidaron como un espacio

7) Nos referimos con esto a la diversidad de situaciones legales en las cuales está la población migrante. Por ello transitaron por el taller migrantes refugiados, solicitantes de refugio, migrantes con residencia en trámite y migrantes con residencia legal.

8) En Uruguay, la población no blanca está conformada por la población afro (8,1\%), indígena (5 \%) y de origen asiático o amarillo (0,5\%), según los datos del censo de 2011. Estos números se corresponden, a su vez, con enormes dificultades de garantías para la población afro, específicamente, de acceso a derechos, ubicándose esta en los percentiles más bajos de pobreza, sobrerrepresentada en las tasas de desempleo y en la población con menos nivel educativo alcanzado, sobre todo las mujeres afrodescendientes (Cabella, Nathan y Tenenbaum, 2013). 
de referencia para los recién llegados. La dimensión religiosa, la diversificación de orígenes (ya no solo a nivel nacional sino continental), la participación de mujeres, y luego de niños y niñas, nos obligó a buscar otras formas de delimitar la población, lo cual derivó en un proceso de emergencia y reconfiguración de demandas no previstas ante distintas situaciones. Asimismo, las denominaciones religiosas y continentales también determinaron un flujo migratorio cuyas configuraciones y arreglos familiares distan de los usuales en nuestra sociedad. Aunque los factores identitarios, como origen nacional, raza y religión, siguen ocupando un lugar importante, no permiten homogeneizar a la población, que puede ser comprendida como un grupo en torno a la barrera idiomática.

El trabajo con poblaciones de orígenes diversos y trayectorias heterogéneas que no representan ni han representado históricamente los principales contingentes poblacionales que han llegado a nuestro país (Taks, 2006) nos exige observar las migraciones en términos de flujos (movilidad permanente) y no de balanzas (número total de inmigrantes y emigrantes). El choque (idiomático, racial, cultural, religioso, etc.) con lo que tradicionalmente se piensa como población migrante en nuestro país, sumado a los desafíos que presenta la ausencia de producción de datos estadísticos, nos obliga a construir categorías propias para delimitar la población con la que trabajamos, de manera de definirla y caracterizarla para generar espacios que posibiliten la construcción de demandas.

A la hora de caracterizar la población con la cual trabajaríamos desde el proyecto presentado, el objetivo principal no fue disolver la diversidad que conforma este grupo poblacional sino buscar mecanismos para agrupar a un colectivo heterogéneo y poder comprender así las trayectorias migratorias, definir problemas y demandas específicas en torno a un denominador común: la barrera idiomática en el contexto de un país de acogida hispanohablante. En esta búsqueda, caracterizamos a este grupo sobre la base de su condición de "migrantes de habla no hispana" en Montevideo y se los invitó a participar en los espacios de enseñanza del español en el marco de un proyecto de extensión.

"Migrantes de habla no hispana" es una categoría precisa pero que no se define por una cualidad común sino por la ausencia de ella, y encierra un conjunto extremadamente diverso de lenguas, orígenes nacionales, pertenencias de clase, étnico-raciales, religiosas, edades e identidades de género. Nuestra formación disciplinar nos orientó a identificar y permanecer alertas de estas diferencias para centrar la mirada sobre la población migrante necesariamente en clave interseccional, entendiendo a esta óptica como imprescindible para comprender la intersección entre diferentes modos de dominación (Viveros, 2016). Estas dimensiones dan forma a trayectorias y proyectos migratorios distintos, a posibles dificultades y obstáculos en su desempeño.

Nuestra experiencia de extensión con personas migrantes no hispanohablantes nos permitió identificar algunos problemas, pero no fue del todo suficiente para construir demandas específicas. En el desarrollo del proyecto, las líneas de trabajo se fueron ampliando y se generaron distintas articulaciones, a veces próximas y otras de desarrollos cada vez más autónomos y específicos.

El proyecto "Buscando redes" fue una forma de potenciar y formalizar el espacio que ya existía en FHCE gestionado por estudiantes y egresados/as de Antropología en función de las demandas concretas de los/as migrantes que habían participado en el período 20152016 - en ese entonces, en su mayoría varones africanos-y de la ONG Idas y Vueltas. EI 
desarrollo del proyecto, en el año 2017, acompañó el trabajo conjunto entre Idas y Vueltas y el NEMMPO, donde se identificaron problemas específicos y se contribuyó a la construcción de demandas. Así, se crearon el espacio de mujeres, "Mujeres de Todos Lados", y el de "Asesoría legal". El equipo de trabajo de "Buscando redes" estuvo compuesto por cuatro integrantes, de los cuales dos terminaron trabajando de manera firme en la conformación de esos espacios, fuera de los talleres en la FHCE.

La experiencia acumulada del trabajo con esta población, principalmente enmarcada en el EFI "De aquí y allá" estuvo en constante articulación con nuestra intervención. De ese modo, algunas de las tareas previstas originalmente para ser abordadas en los talleres en FHCE fueron derivadas a espacios de trabajo concretos y con mayores grados de especialización. Los problemas que conllevan los trámites de residencia y la circulación por distintas dependencias del Estado dejaron de ser tomados como excepcionalidad y fueron trabajados con el conjunto de la población migrante en el espacio de Asesoría legal de Idas y Vueltas. Esta autonomía y especialización constituyó una mejora en la capacidad de respuesta que tenía Idas y Vueltas hasta ese momento, a la vez que permitió que el taller de alfabetización digital y lengua se enfocara en ese objetivo. En lo que refiere al espacio de mujeres, el devenir fue otro. Su construcción reflejó la necesidad de promover y acompañar espacios para migrantes que posibilitaran el diálogo entre sus participantes, en este caso mujeres.

Consideramos que la creación de estos espacios respondió no solo a una demanda de la ONG y de migrantes no organizados, sino que también buscó indagar y acompañar procesos de inserción de las personas migrantes en diferentes niveles —realización de trámites de identificación civil y de residencia, acceso a los sistemas de salud y educativo, acceso al mercado laboral, facilitación de contactos y construcción de redes con otras personas migrantes y practicantes religiosos- y con las especificidades que cada población requiere en función de su país de origen, idioma, edad, situación legal, género, entre otros. La forma de estos espacios en tanto dispositivos de trabajo fue legitimada a través de la experiencia de las clases y talleres de informática realizados entre 2015 y 2017 con la participación constante de una diversidad de migrantes y estudiantes universitarios. Podemos decir, entonces, que la construcción de estos dos espacios que surgieron de manera colateral al taller llevado adelante en la ejecución del proyecto tuvo una continuidad en las estrategias de intervención en el trabajo con la población migrante en Montevideo.

\section{Repensando estrategias, nuevos devenires de la intervención}

Hemos explicitado algunos de los problemas de la construcción de un espacio-taller orientado a una población delimitada por la negativa - no hispanohablante-. Ahora bien, ¿cuál fue el norte que tomó este proyecto una vez creados los espacios de mujeres y de Asesoría legal? ¿Cuáles fueron las "nuevas" demandas que tuvieron lugar en esta etapa? Estas preguntas orientaron nuestra intervención tras la creación de estos espacios y de la participación anterior de migrantes en el taller de alfabetización informática y de idioma. Algunas respuestas y reflexiones solo las podemos esbozar hoy, tras haber tomado distancia de un proceso orientado por la acción y la intervención, puesto que este estuvo permeado por herramientas teórico-conceptuales mediante las cuales fundamentamos actualmente la ruta tomada. 
Sobre la marcha del proyecto, acompasada por la creación de estos dos espacios, la participación fue variando y a largo plazo mermó. El taller de español e informática se tornó en un espacio de participación nuevamente de migrantes africanos, varones y mujeres. Uno de los aspectos centrales de las transformaciones en la participación de estos/ as migrantes en talleres deviene de la construcción identitaria de cada uno/a de ellos/as. Precisamente, la intersección de las diferentes dimensiones de sus identidades los acerca y los aleja de otros participantes de los talleres. Las demandas e intereses diferenciados para cada grupo no están definidos a priori o son intrínsecos a los grupos específicos, sino que se construyen de modos complejos junto con las identidades que los definen. Siguiendo a Femenías:

"Sin embargo, si bien los sujetos son sus identidades (en plural), no las asumen pasivamente: las aceptan o rechazan, las modifican, las rearticulan, las usan y/o las refuncionalizan, en un movimiento permanente de construcción subjetiva y al mismo tiempo político-colectiva. Precisamente, la movilidad identitaria facilita el surgimiento de una red dispersa de significados denominados 'nuevas identidades', producto de los 'nuevos agentes sociales'; es decir, de los elementos sociales más dinámicos de los movimientos de autoafirmación, según un amplio espectro sociopolítico". (2008:18)

Para analizar este proceso nos parece pertinente describir y comprender los elementos que facilitaron la creación de una comunidad africana en Montevideo conformada mayoritariamente por participantes del taller de informática y español. Como mencionamos, muchos/as de quienes participaron en los talleres eran de diversos países africanos, y no solo todos compartían la demanda de mejorar su comprensión del idioma español y sus conocimientos digitales sino que no se sentían a esas alturas cómodos en los otros espacios de Idas y Vueltas que había en ese entonces. Estas percepciones se mencionaron explícitamente en el taller cuando hablamos con algunos de los varones africanos que hacía más de un año participaban en él. En una de estas conversaciones, uno de ellos nos dijo que quería generar un lugar donde pudieran ser bienvenidas las personas de África, seguir sus trámites, acompañar su proceso de búsqueda de vivienda, trabajo, entre otras cosas. Le dijimos que eso ya lo hacía Idas y Vueltas; a lo que nos respondió: "Idas y Vueltas es para dominicanos ahora", haciendo referencia al creciente flujo de dominicanos en Uruguay y a su presencia en la organización.

Debemos entonces enmarcar esta "comodidad" en la clave que nos propone Femenías (2008) sobre el vínculo entre las identidades de los sujetos y la construcción de colectivos políticos de reivindicación identitaria, donde la esencialización de estas identidades es una condición para la conformación de estos grupos. No obstante, esta construcción identitaria se complejiza en la misma diversidad que opera como un gran paraguas que cubre a "quienes provienen de África". Dentro de este enorme grupo, a partir de nuestra experiencia de trabajo y acompañamiento a estos migrantes, pudimos identificar una diferencia marcada entre quienes vienen de países angloparlantes (Nigeria principalmente, y Gambia) y los francófonos (en especial Camerún, Angola y el Congo). Esta distinción también está marcada por 
sus religiosidades, ${ }^{9}$ las cuales están vinculadas en forma directa con diferentes Iglesias, una jesuita (en el caso de francófonos) y otra metodista (en el caso de los nigerianos).

Fuimos invitados a participar de la primera reunión del colectivo realizada en la iglesia jesuita en un barrio de Montevideo en calidad de estudiantes que llevábamos adelante el taller de informática y español, del cual la mayoría formaba parte. Acudimos allí conociendo a la mayoría de sus integrantes, varones, mujeres y niños/as provinientes del Congo, Camerún, Angola, con la excepción de un varón de Nigeria —único angloparlante de la reunión-. Esa oportunidad nos permitió asistir a la conformación de una comunidad cuyo objetivo se orientaba al acompañamiento que se había dado tanto desde Idas y Vueltas como desde el espacio que nosotros sosteníamos en la FHCE y que ahora tomaba su propio rumbo. Las palabras de uno de los interlocutores ilustran este pasaje y el norte de esta colectividad.

"Tenemos la necesidad de actuar como comunidad [y enfatiza esta palabra], no podemos quedarnos en discursos, hay que actuar en colectivo. Si el hijo de alguien tiene un problema todos debemos ayudar. Necesitamos una comunidad para ayudarnos, para sacar la cédula, para ir al MIDES ${ }^{10}$, Para cuando vengan otros poder ayudar. Tenemos que hacer muchos papeles sin ayuda, sin saber cómo funciona, evitar ese estrés. Marta ${ }^{11}$ nos ayuda, nos da comida pero no puede hacerlo para siempre. Como africanos tenemos que unirnos y ayudarnos entre nosotros". (Diario de campo, agosto de 2017, traducción momentánea de un integrante del equipo)

Este pasaje demuestra los objetivos de un colectivo así como el vínculo que este tiene con Idas y Vueltas. No es solo ilustrativo del objetivo de la comunidad —como ellos/as mismos/as se designaron como grupo- en sí misma que manifesta explícitamente las demandas de migrantes africanos, sino que demuestra el proceso de construcción de un colectivo con cierto grado de autonomía. En este sentido, pensamos también que el llamado horizonte de autonomía al cual se orientan los proyectos de extensión universitaria (Sarachu, 2004) también tiene su correlato en procesos no productivos sino de construcción de espacios, de redes y de colectividades que asuman posturas políticas. Si bien sabemos que estos procesos no se dieron en absoluto de forma tutelar en este caso, pues la iniciativa fue propia de migrantes africanos, consideramos que la creación de espacios de diálogo e intercambio fue el terreno fértil para que se construyeran vínculos que devinieran en formas de organización político-ciudadana.

En lo que refiere a la decisión sobre quiénes conforman esta colectividad, podemos decir, sobre la base de la dicotomía que observamos durante el desenvolvimiento del proyecto, que existe una división tácita entre migrantes nigerianos/as y el resto de la población migrante de origen africano. Encontramos interesante pensar cómo se configuran las identidades en torno a la necesidad de politizarse; es decir, cuáles son los elementos que hacen posible que los individuos migrantes ponderen unas dimensiones de su identidad por sobre las otras. Femenías (2008) nos propone pensar que existe siempre una "identidad prevaleciente"

9) Nos gustaría destacar que este aspecto es esencial en la vida de las personas migrantes con quienes trabajamos, sobre todo de estos sujetos cuyas vidas pasan en gran medida por las prácticas y discursos religiosos. Sin embargo, en esta oportunidad nos hemos reducido a mencionar su centralidad e importancia como elementos distintivos y diferencias entre las diferentes poblaciones migrantes.

10) Ministerio de Desarrollo Social.

11) Nombre ficticio de una de las integrantes de la ONG Idas y Vueltas. 
que resulta de la ecuación necesidad y urgencia en la vida de las personas, pues es este el factor que opera en la construcción de colectivos basados en la reivindicación identitaria orientados a la acción y a la intervención.

Esta jerarquización que realiza la población migrante africana se puede ver en varios ámbitos, pero decidimos señalar dos de ellos. En primer lugar, si esta comunidad está signada por el idioma francés es porque está conformada por personas migrantes cuyo origen nacional es francófono, en contraposición a los angloparlantes. Es una afinidad identitaria y política basada en dos aspectos claves: por un lado, la religiosidad ya mencionada, y por otro, más esencial aún, la variable lingüística. En relación con este último punto, durante nuestra presencia en la reunión de conformación de la colectividad africana, uno de los integrantes - quien participaba por segundo año consecutivo en nuestro taller- consultó: "¿Y qué hacemos con Haití?". Esta pregunta ilustra los puntos de conexión entre migrantes de países de continentes diferentes pero hablantes de una misma lengua (a pesar de las variaciones regionales) y sobre quienes se proyectan categorías raciales similares. A partir de nuestras conversaciones en torno a la creación de la comunidad africana y de nuestra presencia en la reunión donde se comenzó a gestar la misma, pudimos ver que no pretendía tener diálogo con la colectividad nigeriana existente en Montevideo; se hizo evidente la dimensión política y estratégica de una noción - "africanos"— que tiene un sentido específico en el Uruguay como contexto de acogida.

En segundo lugar, la convocatoria al espacio de mujeres que mencionamos con anterioridad - "Mujeres de todos lados" - también nos invita a ver cómo dialogan las diferentes identidades de las personas en torno a la necesidad de nuclearse con sus pares. El espacio de mujeres se caracterizó como de intercambio y diálogo entre mujeres principalmente de origen latinoamericano —Brasil, Perú, Cuba, República Dominicana, Haití, y África en menor medida - no necesariamente de habla no hispana, que compartían proyectos migratorios propios, culpas y añoranzas de sus núcleos familiares en sus países de orígenes y experiencias de trabajo precarizado en un mercado orientado a la población migrante muy segmentado en términos de género (Uriarte y Urruzola, 2019). Si bien varias mujeres nigerianas, camerunesas y haitianas participaban del taller de informática y español durante la ejecución del proyecto, no encontraron en el espacio de mujeres un lugar para ellas y no continuaron con su participación allí. Con esto no queremos decir que fuera un espacio orientado a mujeres efectivamente "de todos lados", sino que entendemos que la decisión de no participar de estos espacios respondió, por una parte, a las distancias culturales, sobre todo pensando en las mujeres africanas, en sus diferencias en las concepciones en torno a los lugares socialmente atribuidos a varones y mujeres, a sus arreglos y configuraciones familiares; y por otra, a la necesidad de participar de un espacio en donde existiera un sentido de pertenencia común respecto de lo regional, lo lingüístico y lo religioso. El caso de una familia polígama ejemplifica las distancias en las concepciones sobre prácticas de cuidados, sobre el amor y la familia que distan no solo de los sentidos que les otorgamos las personas uruguayas sino también del compartido por las migrantes latinoamericanas. A su vez, también identificamos en estas mujeres la necesidad de conformar grupos mixtos en donde el liderazgo debía ser masculino. El siguiente fragmento de diario de campo alude a la intervención de una de las mujeres integrante de la familia polígama en torno a la discusión de quién debía ser la persona indicada para liderar esta comunidad. 
"Cuando una de las mujeres del Congo interviene con relación a quién será el líder dice: 'La mujer en África debe dejar el lugar al hombre. Aquí todos debemos ayudarnos. Congoleses, angoleños, cameruneses, haitianos. Tenemos deseos de estar juntos, de sonreír, de comer comida africana juntos, como hermanos. ¿Por qué no hacemos eso? Cuando vengan otros africanos deben sentir la confianza en sus hermanos africanos'". (Diario de campo, agosto de 2017, traducción simultánea de un integrante del equipo)

Estas palabras ilustran tanto los objetivos comunitarios y de identidad francoparlante de los migrantes como la enunciación de formas de organización social y política donde la participación de las mujeres es subordinada al liderazgo de un varón. Esto deja en claro que formar parte de un grupo únicamente de mujeres no es una opción para ella. Debemos tomar en consideración, entonces, que los colectivos de mujeres albergan dentro de esta gran categoría — la de mujer - una diversidad de identidades cuya intersección no siempre es operativa para la generación de un espacio de construcción, acción e intercambio colectivo para todas las personas que identificamos como mujeres. Como señala Viveiros (2016), cada categoría encierra una enorme diversidad que debemos poner en diálogo con otros aspectos de la identidad para lograr una mayor comprensión sobre cómo operan y se construyen los mecanismos de dominación. En un mismo sentido, la autora señala la distancia que se empezó a generar entre los movimientos sociales que reivindicaron inicialmente esta perspectiva y el mundo académico. Por ello, en la articulación del trabajo conjunto con Idas y Vueltas encontramos clave la perspectiva interseccional en la construcción de espacios y en la intervención en el campo. Femenías (2008) analiza a la perfección la intersección entre estos aspectos.

"En síntesis, el colectivo de mujeres es complejo y los entramados de solidaridad étnica (de clase, de religión, etc.) que se producen en su interior deben iluminarse en la medida en que producen efectos significativos para el colectivo en general. $Y$ no para desestimar lo universal, sino precisamente para que sepamos por qué resulta tan rechazado, de tan difícil aplicación y, además, arrastra tras de sí un tendal tan significativo de excluidos/as". (p. 25)

\section{Conclusiones}

En lo que refiere a las estrategias de intervención, empezamos por consolidar el trabajo y las experiencias previas - sistematizando y generando líneas de análisis- y luego dimos continuidad al espacio de alfabetización digital y español — cuyo alcance no se limitó a los encuentros semanales y objetivos formales-. La retroalimentación de estos dos puntos contribuyó a la consolidación de un espacio de confianza que habilitó diversas actividades, diálogos y expresiones, y esas habilitaciones fueron fundamentales para conocer los procesos que vivieron estas personas al llegar a nuestro país e identificar brechas entre los derechos garantizados por el marco jurídico y su real acceso y ejercicio. Los talleres de informática y español resultaron centrales en el proyecto que llevamos a cabo, dado que posibilitaron la profundización de redes y contactos que desencadenaron en instancias como la construcción de un espacio propio de migrantes africanos al que fuimos invitados a participar.

Sin embargo, dada la apertura y el continuo diálogo entre el equipo y los actores no universitarios, las estrategias de trabajo se reorientaron en algunos sentidos. Estos cambios, 
que podrían considerarse una dificultad, produjeron varias aperturas para el proyecto. La construcción de espacios desde migrantes y de migrantes en conjunto con integrantes del equipo, con distintos niveles de autonomía, en el sentido de Sarachu (2004) en cuanto a las organizaciones existentes, ampliaron de manera significativa los alcances del proyecto. Consideramos que estas reorganizaciones fueron sumamente fructíferas al generar aperturas a las demandas concretas de los actores involucrados y visibilización de las especificidades que cada población requiere. Como sostiene Rebellato (2015) pensando en el Trabajo Social, "no ser rígido nunca es sinónimo de no ser riguroso" (p. 78), y es la constante actitud investigativa la que debe apuntar a una rigurosidad sostenida sobre la "escucha" y la confianza en los procesos de los sectores con los que se trabaja.

La categoría de "migrantes de habla no hispana" operaba, al inicio, reuniendo al grupo de migrantes que tenía una demanda concreta: mejorar o comenzar a desarrollar su conocimiento de la lengua. Por ello, la iniciativa del proyecto fue mantener este espacio y, a la vez, debido a la participación de estos/as migrantes y a sus percepciones sobre dicho espacio, mantuvimos el objetivo de acompañar el tránsito por los diferentes organismos estatales de aquellos que debían acudir para realizar trámites. Muchas de las dificultades que encontramos en ese tránsito estaban directamente relacionadas con las dificultades idiomáticas.

No obstante, en varias situaciones no fue suficiente para contemplar las demandas y necesidades no satisfechas por parte de la población. Género, orígenes nacionales, edad, religiosidad y arreglos familiares, fueron variables que a través del trabajo de campo interpelaron el sentido de la categoría que habíamos diseñado para nuestra intervención. Visualizar esta complejización dio paso a una reformulación con relación a:

- Las estrategias mediante las cuales llevamos adelante los talleres de español, intentando coordinar y planificar los objetivos del espacio en conjunto con quienes asistían a él, sobre todo con quienes sostuvieron dicha participación durante más tiempo. En el comienzo eran talleres más parecidos a una dinámica de clase: aprendizaje-enseñanza de español, y luego fuimos incorporando la computadora, actividades como realización de curriculum y utilización de páginas web del Estado. Estas experiencias llevaron también a que en 2017 hubiera un grupo de español para migrantes dictado por el Centro de Lenguas Extranjeras de la FHCE.

- Pensar y articular abordajes para la situación de las mujeres después de detectar vínculos dispares en función de arreglos familiares, orígenes nacionales y pertenencias étnico-raciales. "Mujeres de todos lados" constituyó un espacio de acompañamiento y contención para muchas migrantes - sobre todo latinoamericanas-, pero no para aquellas que asistían a los talleres en la FHCE (como previmos en un momento). Algunas mujeres - principalmente africanas - encontraron un lugar desde donde canalizar otras demandas en espacios mixtos con migrantes con quienes compartían orígenes.

- Las estrategias para realizar el acompañamiento por organismos estatales y realizaciones de trámites. Para eso, el desarrollo se dio de manera cada vez más específica y separada de los otros espacios y con una participación central de estudiantes y recién egresados/as de Relaciones internacionales. Muchas dificultades no son exclusivas de quienes no hablan la lengua. Ante todo, emerge la necesidad de contemplar la especificidad que requiere el mundo legal y normativo, esencial para el ejercicio efectivo de los derechos de los/as migrantes. 
Uno de los resultados evidentes de la intervención que potenció este proyecto, junto con el trabajo de Idas y Vueltas, fue la conformación de un colectivo-comunidad de africanos en Uruguay. Este colectivo se constituyó con el objetivo de fortalecer vínculos entre migrantes africanos/as en Montevideo y generar un grupo de contención para ellos.

Los niveles de involucramiento de nuestro equipo respecto de la población objetivo de este proyecto variaron dependiendo de las estrategias, formas y tipos de intervención. La flexibilidad en los mecanismos de evaluación y la reformulación a partir de lo observado en distintas oportunidades fue central para que los cambios en las estrategias del proyecto no perdieran de vista los objetivos principales y no se estancaran o desencadenaran en una experiencia desarticulada del encuadre de trabajo más amplio entre el NEMMPO e ldas y Vueltas.

Como describimos y analizamos, la categoría "migrantes de habla no hispana" resultó operativa para el proceso de trabajo a pesar de su amplitud abarcativa. Entendemos que su laxitud nos permitió transitar un recorrido que implicó un proceso de construcción de demandas particulares dentro de la diversidad de migrantes con quienes trabajamos. Es por ello que el desarrollo del proyecto operó como un catalizador de los desafíos particulares que implicaba cada una de las poblaciones a la hora de pensar procesos de integración, a la vez que en cada taller se veían reunidos migrantes cuyo denominador común era la exclusión de la lengua de facto de Uruguay: el español. El atributo que los incluía era el mismo que los excluía de la sociedad uruguaya.

Nos interesa particularmente destacar la importancia de los procesos de reflexión a partir de los cuales se pueden reabrir y replicar experiencias en el marco de la extensión universitaria. Sostenemos, para nuestro trabajo, que los proyectos desarrollados en este contexto deben estar abocados a la generación de experiencias que logren procesar los caminos recorridos de manera conjunta entre actores universitarios y sociedad civil. En ese sentido, encontramos en los proyectos de extensión una valiosa herramienta para crear insumos a partir del diálogo con las poblaciones con las que trabajamos, contemplando sus diversidades y enunciando sus especificidades en términos de estrategias de intervención.

\section{Referencias bibliográficas}

Cabella, W.; Natham, M. y Tenebaum, M. (2013). Atlas Sociodemográfico y de la Desigualdad del Uruguay. La población afro-uruguaya en el Censo 2011. Montevideo: Trilce. Recuperado de: http://www.ine.gub.uy/ documents/10181/34017/Atlas_fasciculo_2_Afrouruguayos.pdf/ec7ecb3f-ca0a-4071-b05f-28fdc20c94e2 (consultado el 14 de junio de 2019).

Femenías, M.L. (2008). Identidades esencializadas/violencias activadas. ISEGORÍA. Revista de Filosofía Moral y Política, (38, enero-junio), 15-38. Recuperado de: http://www.acuedi.org/ddata/10982.pdf (consultado el 14 de junio de 2019).

Fossatti, L. \& Uriarte, P. (2018). Viviendo sin derecho. Migraciones latinoamericanas y acceso a la vivienda en Montevideo. La Rivada, 6(11), 42-60. Recuperado de: http://larivada.com.ar/index.php/numero-11/101-3-articulos/190-viviendo-sin-derecho (consultado el 14 de junio de 2019).

Gómez, G.; Curbelo, M. \& Uriarte, P. (2018). Informe de sistematización del Espacio de Formación Integral "De aquí y de allá. Migraciones contemporáneas en el Uruguay". Unidad de Extensión, FHCE-UdelaR. Inédito. Grimson, A. (2011). Los límites de la cultura: crítica de las teorías de la identidad. Buenos Aires: Siglo Veintiuno Editores 
Guigou, L.N. (2000). De la religión civil: identidad, representaciones y mito-praxis en el Uruguay. Algunos aspectos teóricos. En Romero, S. (Comp.). Anuario de Antropología Social y Cultural en Uruguay. Montevideo:Dpto. de Antropología Social, FHCE, Fontaina-Minelli-Nordan.

Jara Holliday, O. (s/f). La concepción metodológica Dialéctica, los Métodos y las Técnicas Participativas en la Educación Popular. Centro de estudios y publicaciones Alforja (CEP) Recuperado de: https://trabajosocialsantafe.org/wp-content/uploads/2019/02/Jara-Sistematizacion.pdf (consultado el 14 de junio de 2019).

Llopis, R. (2007). El nacionalismo metodológico como obstáculo en la investigación sociológica sobre migraciones internacionales. EMPIRIA Revista de metodología de Ciencias Sociales, (13, enero-junio), 101-117. Recuperado de: http://www.redalyc.org/pdf/2971/297124012005.pdf (consultado el 14 de junio de 2019).

MIDES (2017). Caracterización de las nuevas corrientes migratorias en Uruguay. Montevideo: Ministerio de Desarrollo Social. Recuperado de: http://eva.fhuce.edu.uy/pluginfile.php/40696/mod_resource/content/0/libromigrantes_versionweb_hb_1.pdf (consultado el 14 de junio de 2019).

Rebellato, J.L. (2015). La contradicción en el trabajo de campo. Cuadernos de extensión Nº 4. Formulación de proyectos de extensión universitaria, 87-92. Montevideo: CSEAM, UdelaR.

Sarachu, G. (2004). Prácticas integrales: fundamentos, recorridos y experiencias participativas desde la extensión universitarias. En Prácticas Académicas Integrales en el cono Sur. Colección temática PROCOAS. Universidad y trabajo asociado. Extensión Libros.

Sassen, S. (2006). La formación de las migraciones internacionales: implicaciones políticas. Revista Internacional de Filosofía Política, (27). Recuperado de: http://e-spacio.uned.es/fez/eserv/bibliuned:filopoli-2006-27-379 38CE5-086B-6191-7366-5BDBADF72E0E/formacion_de_migraciones.pdf (consultado el 14 de junio de 2019). Sayad, A. (2008 [1984]). Estado, nación e inmigración. El orden nacional ante el desafío de la inmigración. Apuntes de Investigación, 13, 101-116. Recuperado de: http://eva.fhuce.edu.uy/pluginfile.php/111175/mod_ resource/content/1/estado\%20nacion\%20e\%20inmugracion (consultado el: 14 de junio de 2019).

(2010 [1996]). Colonialismo y migraciones. Elementos para una sociología de la inmigración. Selección de textos de Abdelmalek Sayad. EMPIRIA Revista de metodología de Ciencias Sociales, (19, enero-junio).

Segato, R.L. (2006). Racismo, discriminación y acciones afirmativas: herramientas conceptuales. Serie Antropología, 404. Brasilia. Recuperado de: http://blog.utp.edu.co/etnopediatria/files/2015/03/Rita-Laura-SegatoRacismo.pdf (consultado el 14 de junio de 2019).

Taks, J. (2006). Migraciones internacionales en Uruguay: De país trasplantado a diáspora vinculada. THEOMAI. Estudios sobre Sociedad, Naturaleza y Desarrollo, 12(segundo semestre). Buenos Aires.

Tilly, C. (2000 [1998]). La desigualdad persistente. Buenos Aires: Manantial.

Uriarte, P.; Urruzola, J. (2018). Las mujeres, los niños y las niñas también migran. Corrientes migratorias latinoamericanas en Uruguay desde una perspectiva de género. Encuentros Latinoamericanos (Segunda Época) ENCLAT, 2(2), 23-48. Recuperado de: http://ojs.fhuce.edu.uy/index.php/enclat/article/view/123 (consultado el 14 de junio de 2019).

Uriarte, P. (2007). Perigoso é não correr perigo. Tese de Doutorado. UFRGS, Porto Alegre.

Uriarte, P. \& Montealegre. (2018). Al menos un puñado de gurises. Atenea Digital, 18(1), 91-112. Recuperado de: https://doi.org/10.5565/rev/athenea.2217 (consultado el 14 de junio de 2019).

Uriarte, P. \& Ramil, R. (2016). Racismo epistemológico y antropologías locales, reflexiones sobre una experiencia. Jornadas Académicas sobre Afrodescendencia, MIDES, Uruguay.

Viveros, M. (2016). La interseccionalidad: una aproximación situada a la dominación. Debate Feminista, (52), 1-17. Recuperado de: http://www.debatefeminista.cieg.unam.mx/wp-content/uploads/2016/12/articulos/052_ completo.pdf (consultado el 14 de junio de 2019). 